\title{
Produção de matéria seca e eficiência nutricional para P, Ca e Mg em leguminosas herbáceas
}

\author{
Antonio Rodrigues FERNANDES ${ }^{1}$, Francisco Ilton de Oliveira MORAIS ${ }^{2}$, Lílian Cristiane Fernandes \\ LINHARES $^{3}$, George Rodrigues da SILVA ${ }^{1}$
}

\begin{abstract}
RESUMO
As leguminosas para adubação verde têm sido introduzidas nos sistemas agrícolas para a recuperação de solos desgastados pelo uso intensivo. O objetivo desse trabalho foi avaliar a resposta de leguminosas herbáceas à aplicação de calcário e fósforo sobre a produção de biomassa e eficiência nutricional para o P, Ca e Mg. O experimento foi desenvolvido em casa-de-vegetação do Departamento de Ciência do Solo da Universidade Federal Rural da Amazônia, utilizando-se um Latossolo Amarelo distrófico coletado na profundidade de 0 - $20 \mathrm{~cm}$, em Belém, PA. O delineamento experimental usado foi o de blocos ao acaso, com arranjo de tratamentos em um fatorial $3^{3}$, onde foram comparadas três espécies de leguminosas: mucuna preta (Stizolobium atterrimum), mucuna cochinchinensis (Stilozobium cochinchinensis) e feijāo-de-porco (Canavalia ensiformes); três níveis de calagem: de calcário dolomítico $\left(0,4 \mathrm{e} 8\right.$ t.ha $\left.{ }^{-1}\right)$ e de fósforo $(0$, 25 e $45 \mathrm{mg} \cdot \mathrm{dm}^{-3}$ ), com quatro repetiçóes cada um. Mucuna cochinchinensis e o feijão de porco produziram maiores quantidades de biomassa vegetal do que a mucuna preta, sendo que a primeira espécie acumulou maior quantidade de $\mathrm{P}$ e a segunda maior quantidade de Ca. Mucuna cochinchinensis apresentou maior eficiência de utilização de P, Ca e Mg na ausência da calagem. Nos solos intemperizados com baixa concentração de $\mathrm{P}, \mathrm{Ca}$ e $\mathrm{Mg}$, o feijão-de-porco e a mucuna cochinchinensis poderão ter melhor desempenho do que a mucuna preta, visto que apresentaram maior eficiência de translocação e de utilização desses nutrientes, respectivamente.
\end{abstract}

PALAVRAS-CHAVE

Calagem, adubação fosfatada, absorção de nutrientes, translocação de nutrientes, eficiência de utilização de nutriente.

\section{Dry matter production and nutritional efficiency for $P$, Ca and Mg in herbaceous legumes}

\begin{abstract}
The legumes used for green manure have been introduced in agricultural systems for recovering degraded soils by intensive use. The objective of this work was to evaluate the response of herbaceous legumes to liming and P application on dry matter and its nutritional efficiency. The experiment was developed in greenhouse at the Soil Science Department of the Federal University Agricultural of Amazon (Brazil). Soil used was a dystrophic Yellow Latosol, sampled in the $0-20 \mathrm{~cm}$ depth. A randomized block experimental design was used with treatments arranged in a factorial 33, comparing three legume species: velvet bean (Stizolobium atterrimum), "mucuna cochinchinensis"(Stilozobium cochinchinensis) and jack bean (Canavalia ensiformes); three doses of liming ( 0 , 4 and 8 tha ( $^{-1}$ oflimestone) and of triple superphosphate $(0,25$ and $45 \mathrm{mg} \mathrm{P} \mathrm{dm}$-3 of soil), with four replications each one. Results showed that "mucuna cochinchinensis" and jack bean produced higher amounts of dry matter than velvet bean. The first species accumulated higher amount of $P$ and the second species higher amount of Ca in the tissue. The "mucuna cochinchinensis" species showed higher use efficiency of Ca, Mg and P in the absence of liming. The jack bean and mucuna cochinchinensis can have better performance than velvet bean, in weathered soils with low concentration of P, Ca and Mg, since they presented higher translocation efficiency and use of these nutrients, respectively.
\end{abstract}

KEYWORDS

Liming, phosphate fertilization, nutrient uptake, nutrient translocation, nutrient use efficiency.

'Engenheiro Agrônomo, Dr., Professor Adjunto do DCS/UFRA.

${ }^{2}$ Engenheiro Agrônomo, PhD., Professor Visitante do DCS/UFRA.

${ }^{3}$ Engenheira Agrônoma, Aluna de Mestrado do DCS/UFRA 


\section{INTRODUÇÃo}

Na regiáo Amazônica os solos têm sido submetidos a um manejo inadequado com conseqüente deterioração das qualidades físicas, químicas e biológicas, levando à perda de sua capacidade produtiva. Cerca de $70 \%$ dos solos da região são representados por Latossolos e Argissolos (Rodrigues, 1996), os quais geralmente apresentam elevada acidez, saturação em $\mathrm{Al}$ e Mn trocáveis, associados a uma baixa concentração de nutrientes, principalmente P disponível, Ca e Mg (Sanches, 1981; Vieira $\&$ Santos, 1987).

A utilização de leguminosas como cobertura e/ou adubação verde surge como uma importante prática de manejo desses solos, pois estas possibilitam o aumento do rendimento das culturas que as sucedem, pela redução da erosão, conservação de água, reciclagem de nutrientes (Calegari et al., 1993) e melhoria das características físicas, químicas e biológicas dos solos (Kage, 1984).

As leguminosas usadas para adubação verde, apesar de serem consideradas rústicas têm apresentado respostas expressivas à adubação fosfatada e à calagem (Carvalho et al., 1988) ou não têm se desenvolvido satisfatoriamente em solos com baixa fertilidade natural (De-Polli \& Chada, 1989). Para aperfeiçoar o uso destas espécies, é necessário identificar as mais adaptáveis às condições edáficas da região e adequá-las à melhor forma de manejo. Assim sendo, a seleção de espécies adaptadas às condiçōes adversas de fertilidade do solo, notadamente à carência de $\mathrm{P}, \mathrm{Ca}$ e Mg, seria muito importante para aumentar a eficácia no uso da adubação fosfatada e da calagem, visando a sustentabilidade dos sistemas produtivos.

A produção de biomassa é uma das características mais importantes das leguminosas utilizadas como adubos verdes. Entretanto, existe uma grande variação de produção entre as espécies em função das condições edafoclimáticas nas quais são cultivadas, que pode ser resultado de um comportamento nutricional diferencial (Alvarenga et al., 1995).

Espécies mais eficientes na absorção, translocação e utilização de nutrientes poderão ser mais interessantes para uso no manejo de solos com baixa fertilidade natural, por apresentarem maior capacidade de adaptação e melhor desempenho (Caldeira et al., 2002).

O presente trabalho teve como objetivo avaliar o desempenho de três espécies leguminosas utilizadas para adubação verde, quanto à produção de matéria seca e eficiência nutricional, sob o efeito de doses diferenciadas de calcário e de fósforo em um Latossolo Amarelo distrófico.

\section{MATERIAL E MÉTODOS}

$\mathrm{O}$ experimento foi instalado e conduzido em casa-devegetação, localizada no campus da Universidade Federal Rural da Amazônia (UFRA). Amostras de um Latossolo Amarelo distrófico foram coletadas na profundidade de $0-20 \mathrm{~cm}$, numa área de vegetação secundária com mais de 40 anos de idade, situada à margem esquerda da estrada de acesso à UFRA, ao lado de uma plantação de dendê, pertencente ao CPATU/ EMBRAPA. Depois de destorroado, homogeneizado, seco ao ar e peneirado em malha de dois milímetros, foram tomadas amostras de terra, em triplicata, para as análises químicas, no laboratório do Departamento de Solos da UFRA. A determinação do valor médio de $\mathrm{pH}$ em água $(1: 2,5)$, das concentraçôes de $\mathrm{P}, \mathrm{K}, \mathrm{Ca}$, $\mathrm{Mg}, \mathrm{H}$, Al e do carbono (Tabela 1), conforme metodologia da EMBRAPA (1997).

Tabela 1 - Características químicas do solo estudado (camada 0-20 cm de profundidade).

\begin{tabular}{cccccccc}
\hline $\mathrm{pH}$ & $\mathrm{C}$ & $\mathrm{P}$ & $\mathrm{K}^{+}$ & $\mathrm{Ca}^{2+}$ & $\mathrm{Mg}^{2+}$ & $\mathrm{H}^{+}$ & $\mathrm{Al}^{3+}$ \\
\hline $\mathrm{H}_{2} \mathrm{O}$ & $\mathrm{G} \mathrm{dm}^{-3}$ & \multicolumn{2}{c}{$\mathrm{mg} \mathrm{dm}^{-3}$} & & $--\mathrm{Cmol}_{\mathrm{c}} \mathrm{dm}^{-3}$----- & \\
3,7 & 29,7 & 3,5 & 261 & 0,05 & 0,05 & 5,99 & 2,11 \\
\hline
\end{tabular}

O delineamento experimental foi o de blocos ao acaso, com quatro repetiçōes. Os tratamentos foram arranjados em um esquema fatorial de $3 \times 3 \times 3$, assim especificado: três espécies de leguminosas, três doses de calcário e três doses de superfosfato triplo.

Foram utilizados vasos plásticos com capacidade para 3,3 $\mathrm{dm}^{3}$ de solo, apresentando furos no fundo, de modo a permitir o escoamento do excesso de água, que era recolhido nos pratos e devolvido aos vasos. Para a calagem, foi utilizado o calcário dolomítico com as seguintes características químicas: $35,9 \%$ de $\mathrm{CaO}, 19 \%$ de $\mathrm{MgO}$ e $61,7 \%$ de poder relativo de neutralização total, nas doses de 0 , 4 e 8 t ha $^{-1}$ (0, 6,6 e 13,2 g de calcário/ vaso), permanecendo incubados durante 88 dias. As duas últimas doses corresponderam a uma e duas vezes a necessidade de calagem para neutralizar o alumínio trocável do solo (Kamprath, 1967). Como fonte de fósforo foi usado o superfosfato triplo, com $46,5 \%$ de P, que foi uniformemente distribuído no solo, a uma profundidade de quatro centímetros nos vasos, nas doses de 0,25 e $45 \mathrm{mg} \mathrm{dm}^{-3} \mathrm{de}$, de acordo com os tratamentos, logo após o período de incubação.

Foram plantadas quatro sementes por vaso das espécies de leguminosas utilizadas: Stizolobium aterrimum (mucuna preta), Stizolobium cochinchinensis (mucuna cochinchinensis) e Canavalia ensiformes (feijão-de-porco), procedendo-se a um desbaste em duas das plântulas, no décimo dia após a semeadura. A umidade dos vasos, tanto no período de incubação quanto no experimental, foi mantida em torno de $70 \%$ do volume total de poros, aferida mediante pesagens periódicas dos vasos, completando-se o peso com água desmineralizada.

A colheita das plantas foi realizada 60 dias após a germinação das sementes. Nesta ocasião, o material vegetal foi separado em partes aéreas e sistema radicular. Em seguida, foram lavados em água corrente desmineralizada, colocados em sacos de papel 
devidamente identificados e levados para a estufa com circulação forçada de ar a $65^{\circ} \mathrm{C}$, até obtenção de peso constante. Após a determinação do peso do material seco, as amostras de plantas foram moídas em moinho tipo Wiley, com abertura de malha de $1 \mathrm{~mm}$. No extrato obtido, por digestão nitroperclórica do material vegetal, foram determinados os teores de P por colorimetria e de $\mathrm{Ca}$ e de $\mathrm{Mg}$ por espectrofotometria de absorção atômica. Calcularam-se a absorção - ABS (mg de nutriente na parte aérea + mg de nutriente na raiz), a eficiência de translocação - EFT (mg de nutriente na parte aérea $\mathrm{mg}^{-1}$ total x 100) e a eficiência de utilização - EFU ( $\mathrm{g}^{2}$ de matéria seca produzida $\mathrm{mg}^{-1}$ de nutriente absorvido).

Os resultados para matéria seca, absorção, eficiência de translocação e de utilização foram submetidos à análise de variância, teste $\mathrm{F}(\mathrm{p}<0,05)$ e ao teste de Tukey $(\mathrm{p}<0,05)$ para comparar as médias. Equações de regressão foram ajustadas relacionando a produção de matéria seca total com as doses de fósforo e/ou de calcário. Testaram-se diversos modelos para as equaçōes ( $1^{\circ}$ e $2^{\circ}$ graus), sendo a escolha baseada no maior coeficiente de determinação e na maior significância. Para todas estas análises, utilizou-se o sistema estatístico SANEST (Zonta \& Machado, 1991).

\section{RESULTADOS E DISCUSSÃO}

\section{PRODUÇÃO DE MATÉRIA SECA TOTAL}

A mucuna preta apresentou uma produção de matéria seca total menor $(\mathrm{p}<0,05)$ do que a mucuna cochinchinensis e o feijão-de-porco (Tabela 2). No Estado do Acre, Gomes \& Pereira (1992) também constataram uma maior produção de matéria seca da mucuna cochinchinensis em relação à mucuna preta, quando cultivadas em um Argissolo Vermelho distrófico. Por outro lado, Carvalho \& Mochiuyyi (1992) obtiveram resultados discordantes dos conseguidos no presente estudo, registrando uma maior produção de matéria seca da mucuna preta em relação ao feijão-de-porco, quando cultivada em um Latossolo Amarelo textura média do Estado do Amapá.

Convém salientar que condições locais podem favorecer não só determinadas espécies em relação a outras como também promover variações de produção dentro da mesma espécie. Trabalhos recentes têm demonstrado haver uma interação entre o genótipo e o ambiente afetando a produção de massa seca dos

Tabela 2 - Matéria seca total (MST) de leguminosas herbáceas (duas plantas por vaso), cultivadas durante 60 dias, em um Latossolo Amarelo.

\begin{tabular}{cc}
\hline ESPÉCIES & MST, g vaso-1 \\
\hline Mucuna preta & $17,4^{\mathrm{b}}$ \\
Mucuna cochinchinensis & $19,9^{\mathrm{a}}$ \\
Feijão de porco & $19,3^{\mathrm{a}}$ \\
\hline Médias nas colunas seguidas de mesma letra não diferem entre si, pelo teste de Tukey a 5\%.
\end{tabular}

adubos verdes e podendo levar a diferentes resultados (Böhringer et al., 1994; Muller et. al., 1992).

Os valores obtidos para a matéria seca total foram ajustados às doses de superfosfato triplo e de calcário aplicadas, por meio de equações de regressão (Figura 1). As leguminosas, de um modo geral, foram beneficiadas tanto pela calagem quanto pela adubação fosfatada, no entanto, a maior produção ocorreu na presença do calcário, sendo que um aumento mais expressivo foi até a dose de $4 \mathrm{t} \mathrm{ha}^{-1}$. Aumentos na produção de matéria seca por leguminosas, em resposta ao fósforo, foram encontrados por Kolling et al. (1976) e Carvalho et al. (1988); no entanto, a eficiência do P aumentou com os níveis crescentes de calcário.

\section{ABSORÇÃO DE NUTRIENTES}

As espécies apresentaram comportamento diferente em relação à absorção de $\mathrm{P}, \mathrm{Ca}$ e $\mathrm{Mg}$ (Tabela 3). A mucuna cochinchinensis acumulou maior quantidade de $\mathrm{P}$, enquanto que o feijão-deporco acumulou mais $\mathrm{Ca}$ e $\mathrm{Mg}$, este último com diferença significativa apenas para a mucuna preta. Tais diferenças na

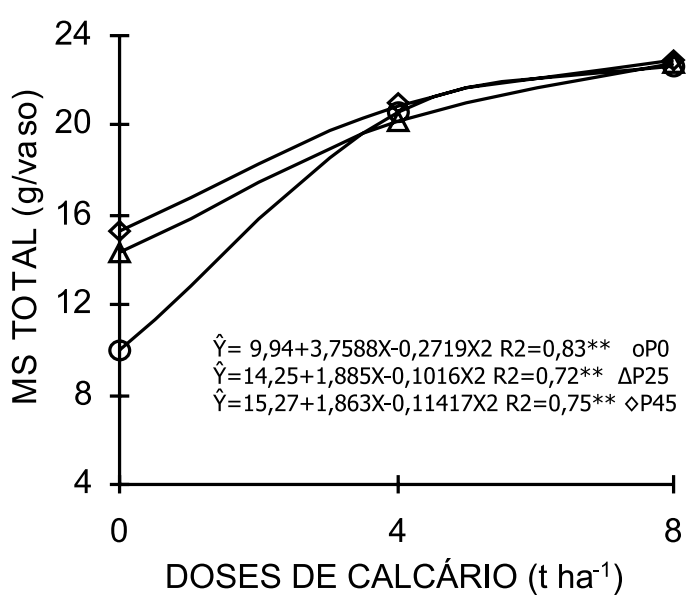

Figura 1 - Relação entre as doses de fósforo $(0=P 0,25=P 25$ e 45=P45, em $\mathrm{mg} \mathrm{dm}^{-3}$ ) e de calcário aplicadas e a produção de matéria seca (MS) total de leguminosas cultivadas durante 60 dias, em um Latossolo Amarelo. ${ }^{* *}$ significativo a $1 \%$ pelo teste $\mathrm{F}$.

Tabela 3 - Absorção média de $\mathrm{P}, \mathrm{Ca}$ e $\mathrm{Mg}$ das leguminosas (duas plantas por vaso), cultivadas durante 60 dias, em um Latossolo Amarelo, submetidas a diferentes doses de $\mathrm{P}$ e de calcário.

\begin{tabular}{cccc}
\hline Espécies & $\mathrm{P}$ & $\mathrm{Ca}$ & $\mathrm{Mg}$ \\
\hline & & $\mathrm{mg} \mathrm{vaso-1}^{-1}$ & \\
\hline $\begin{array}{c}\text { Mucuna preta } \\
\text { Mucuna }\end{array}$ & $37,7 \mathrm{~b}$ & $117 \mathrm{~b}$ & $40,0 \mathrm{~b}$ \\
cochinchinensis & $43,8^{\mathrm{a}}$ & $115 \mathrm{~b}$ & $46,1 \mathrm{ab}$ \\
Feijão de porco & $37,0 \mathrm{~b}$ & $158 \mathrm{a}$ & $48,1 \mathrm{a}$ \\
\hline
\end{tabular}

Médias seguidas pelas mesmas letras, nas colunas, não diferem entre si pelo teste de Tukey a $5 \%$. 
absorção de nutrientes entre as espécies, numa mesma condição de fertilidade do solo, têm sido atribuídas, em muitos trabalhos, a um controle genético. Por outro lado, alguns autores têm relacionado diferenças na absorção de $\mathrm{P}$ por algumas espécies, entre outros fatores, à tolerância à toxidez de alumínio (Vilela \& Anghinoni, 1984; Abichequer \& Bohnen, 1998). Desta forma, poder-se-ia sugerir que a mucuna cochinchinensis é mais tolerante ao $\mathrm{Al}^{3+}$ do que as demais espécies estudadas.

O conteúdo de $\mathrm{P}$ nas plantas cresceu com o aumento nas doses de fósforo e de calcário, sendo que o efeito mais expressivo ocorreu pela interação entre ambas (Tabela 4). Os aumentos proporcionados pelo uso de $25 \mathrm{mg} \mathrm{dm}^{-3} \mathrm{P}$ e de $4 \mathrm{t} \mathrm{ha}^{-1}$ de calcário corresponderam a $116 \%$ e $188 \%$, respectivamente, enquanto que pela interação atingiu $432 \%$. Isto sugere que o bom desempenho destas espécies como acumuladoras e posteriormente recicladoras de nutrientes, em solos com características químicas similares ao utilizado neste estudo, dependerá de um suprimento mínimo de P e da correção da acidez.

A maior capacidade da mucuna cochinchinensis de acumular P e do feijāo-de-porco de acumular $\mathrm{Ca}$ e $\mathrm{Mg}$ podem ter permitido que tais espécies produzissem maiores quantidades de matéria seca, em relação à mucuna preta. Este fato reveste-se de grande importância, pois o que se espera de espécies utilizadas para adubos verdes é que elas produzam matéria seca e reciclem nutrientes em grandes quantidades.

$\mathrm{Na}$ ausência da calagem, não houve diferenças significativas entre as espécies com relação ao conteúdo de $\mathrm{Ca}$, enquanto que o feijão-de-porco apresentou o maior conteúdo de $\mathrm{Mg}$, seguido das mucunas cochinchinensis e preta (Tabela 5). No entanto, com a calagem ocorreu um aumento significativo dos acúmulos de Ca e de $\mathrm{Mg}$, até a dose de $4 \mathrm{t} \mathrm{ha}^{-1}$, com exceção do Ca no feijāo-de-porco que continuou aumentando com doses crescentes de calcário.

\section{TRANSLOCAÇÃO DOS NUTRIENTES}

Os resultados da análise dos nutrientes nos tecidos indicam que as espécies distinguiram-se com relação à translocação de nutrientes para a parte aérea (Tabela 6). O feijão-de-porco foi a

Tabela 4 - Absorção média de $\mathrm{P}$ das leguminosas (duas plantas por vaso), em função das doses de fósforo e de calcário, cultivadas durante 60 dias em um Latossolo Amarelo.

\begin{tabular}{cccc}
\hline Doses de $\mathrm{P}$ & \multicolumn{3}{c}{ Doses de calcário, $\mathrm{t} \mathrm{ha}^{-1}$} \\
\hline $\mathrm{mg} \mathrm{dm}^{-3}$ & 0 & 4 & 8 \\
& & $\mathrm{P} \mathrm{mg} \mathrm{vaso-1}^{-1}$ & \\
0 & $9,5 \mathrm{bB}$ & $27,2 \mathrm{cA}$ & $31,8 \mathrm{bA}$ \\
25 & $20,5 \mathrm{aC}$ & $50,3 \mathrm{bB}$ & $62,2 \mathrm{aA}$ \\
45 & $24,6 \mathrm{aB}$ & $61,7 \mathrm{aA}$ & $67,3 \mathrm{aA}$ \\
\hline
\end{tabular}

Médias seguidas pelas mesmas letras minúsculas, nas colunas, e maiúsculas, nas linhas, não diferem entre si pelo teste de Tukey a $5 \%$. espécie que translocou mais nutrientes, conseguindo manter mais adequadamente os teores dos nutrientes na parte aérea necessários ao metabolismo, enquanto que a mucuna cochinchinensis foi a espécie que translocou menos $\mathrm{Ca}$. Apesar de disto, as espécies produziram a mesma quantidade de matéria seca (Tabela 2), provavelmente devido a diferenças genéticas entre as espécies e a maior eficiência de utilização de Ca pela mucuna cochinchinensis. Diferenças varietais na translocação de $\mathrm{P}$ para a parte aérea e, conseqüentemente, na produção de matéria seca foram constatadas por Martinez (1993) em soja e por Abichequer \& Bohnen (1998) em trigo.

Os tratamentos influenciaram a translocação do $\mathrm{P}$ e do $\mathrm{Ca}$ para a parte aérea, mas não a do $\mathrm{Mg}$ (Tabela 7). $\mathrm{Na}$ ausência da calagem e da adubação fosfatada, ocorreu menor translocação de $\mathrm{P}$ e de Ca por parte das leguminosas. As plantas retiveram maior quantidade de $\mathrm{P}$ e Ca nas raízes em condições de baixo suprimento destes nutrientes, mantendo o crescimento do sistema radicular em detrimento da parte aérea. No caso do P, este fato já foi constatado por vários autores (Loneragan \& Asher, 1967; Martinez et al., 1993; Abichequer \& Bohnen, 1998; Alves et al., 1998). Uma das explicaçōes para isto é que as raízes, estando mais próximas da fonte de suprimento, usam do limitado influxo destes nutrientes para as próprias necessidades de manutenção e crescimento.

\section{EFICIÊNCIA DE UTILIZAÇÃO DOS NUTRIENTES}

As espécies variaram quanto à eficiência de utilização (EFU) dos nutrientes (Tabela 8). A mucuna cochinchinenesis foi mais eficiente na utilização do $\mathrm{P}$, do $\mathrm{Ca}$ e do $\mathrm{Mg}$ do que o feijāo-de-

Tabela 5 - Absorção média de $\mathrm{Ca}$ e de $\mathrm{Mg}$ das leguminosas (duas plantas por vaso), em função das espécies e das doses de calcário, cultivadas durante 60 dias em um Latossolo Amarelo.

\begin{tabular}{|c|c|c|c|c|c|c|}
\hline \multirow[b]{2}{*}{ Espécies } & \multicolumn{6}{|c|}{ Doses de calcário, t ha-1 } \\
\hline & 0 & 4 & 8 & 0 & 4 & 8 \\
\hline & \multicolumn{3}{|c|}{$\mathrm{Ca}, \mathrm{mg}$ vaso $^{-1}$} & \multicolumn{3}{|c|}{$\mathrm{Mg}, \mathrm{mg}$ vaso $^{-1}$} \\
\hline Mucuna preta & $36,9 a \mathrm{~B}$ & $162 a b A$ & $153 \mathrm{bA}$ & $17,4 \mathrm{bB}$ & $52,3 a A$ & $50,3 \mathrm{bA}$ \\
\hline $\begin{array}{c}\text { Mucuna } \\
\text { cochinchinensis }\end{array}$ & $39,2 a B$ & $140 \mathrm{bA}$ & $166 \mathrm{bA}$ & $21,0 \mathrm{abB}$ & $57,8 \mathrm{aA}$ & $59,6 a b A$ \\
\hline Feijão de porco & $42,6 \mathrm{aC}$ & $193 a B$ & $239 a A$ & $25,1 \mathrm{aB}$ & $55,9 \mathrm{aA}$ & $63,2 \mathrm{aA}$ \\
\hline
\end{tabular}

Médias seguidas pelas mesmas letras minúsculas, nas colunas, e maiúsculas, nas linhas, não diferem entre si pelo teste de Tukey a $5 \%$.

Tabela 6 - Translocação média de $\mathrm{P}, \mathrm{Ca}$ e $\mathrm{Mg}$ das leguminosas (duas plantas por vaso), cultivadas durante 60 dias em um Latossolo Amarelo, submetidas a diferentes doses de $\mathrm{P}$ e de calcário.

\begin{tabular}{cccc}
\hline Espécies & $\mathrm{P}$ & $\mathrm{Ca}$ & $\mathrm{Mg}$ \\
\hline & \multicolumn{4}{c}{} \\
\hline Mucuna preta & $80,2 \mathrm{~b}$ & $94,3 \mathrm{~b}$ & $83,9 \mathrm{~b}$ \\
Mucuna cochinchinensis & $80,2 \mathrm{~b}$ & $92,7 \mathrm{c}$ & $83,9 \mathrm{~b}$ \\
Feijão de porco & $88,0 \mathrm{a}$ & $96,1 \mathrm{a}$ & $94,2 \mathrm{a}$ \\
\hline
\end{tabular}

Médias seguidas pelas mesmas letras, nas colunas, não diferem entre si pelo teste de Tukey a $5 \%$. 
porco e a mucuna preta; porém, em relação ao $\mathrm{P}$, não apresentou diferença significativa com o feijāo-de-porco. Ao avaliar a capacidade de conversão dos nutrientes em matéria seca, a eficiência de utilização é um aspecto importante para os adubos verdes, pois estes são cultivados em áreas degradadas ou em degradação, com o fim de recuperá-las e/ou melhorá-las quanto à sua baixa capacidade de suprimento de nutrientes. Neste sentido, Caldeira et al. (2002), trabalhando com espécies florestais, concluíram que a procedência que poderá ter maior produção de biomassa, em solos bastante intemperizados, seria a que apresentasse maior eficiência nutricional.

As leguminosas apresentaram eficiência de utilização dos nutrientes diferenciada em função da variação nas doses de calcário (Tabela 9). Na ausência da calagem, a mucuna chinchinensis foi mais eficiente na utilização dos nutrientes, enquanto que a calagem induziu uma redução na EFU da espécie, que, então, não diferiu estatisticamente das demais espécies na utilização de P e de Mg. No caso do Ca, o feijão-de-porco e a mucuna preta, também foram menos eficientes na sua utilização com o aumento das doses de calcário. Furtini Neto et al. (1999) constataram que duas espécies florestais tiveram a sua eficiência de utilização reduzida para Ca e Mg e aumentada para $\mathrm{P}$, em função da calagem. O melhor desempenho da mucuna cochinchinensis na ausência da calagem sugere uma melhor adaptação às condições de acidez do solo, em que predomina uma baixa disponibilidade de $\mathrm{P}, \mathrm{Ca}$ e $\mathrm{Mg}$.

A interação do calcário com o fósforo diminuiu a eficiência de utilização do $\mathrm{P}$ e do $\mathrm{Mg}$ na dose intermediária de $\mathrm{P}$, não alterando a do $\mathrm{Ca}$ (Tabela 10). A presença do fósforo, na ausência da calagem, aumentou a eficiência de utilização do $\mathrm{Mg}$ e diminuiu a do P, na dose mais elevada. Resultados similares foram constatados por Martinez et al. (1993), enquanto Machado $e t$ al. (1999) obtiveram maior eficácia entre genótipos de milho, de uma maneira geral, no nível mais alto de $\mathrm{P}$ no solo. A menor eficiência no nível mais elevado de $\mathrm{P}$ indicou "consumo de luxo de P” (Jarrel \& Beverly, 1981; Machado, 2000), resultante da acumulação de quantidades crescentes do nutriente, proporcionalmente superior ao crescimento das plantas.

Por outro lado, a calagem, na ausência do fósforo, aumentou a eficiência de utilização de $\mathrm{P}$ (até a dose de $4 \mathrm{t} \mathrm{ha}^{-1}$ ) e de $\mathrm{Mg}$, não alterando a de $\mathrm{Ca}$. Isto pode ser justificado pelo expressivo crescimento provocado pela calagem na ausência do P (Figura 1), sem que a absorção tenha ocorrido na mesma proporção, como mostra a Tabela 4, para o P. Estudando a resposta a calagem de três cultivares de trigo, Bataglia et al. (1985) observaram um aumento de produção sem que houvesse aumento da concentração de P na matéria seca da parte aérea.

Tabela 8 - Eficiência média de utilização de $\mathrm{P}, \mathrm{Ca}$ e Mg das leguminosas (duas plantas por vaso), cultivadas durante 60 dias em um Latossolo Amarelo, submetidas a diferentes doses de $\mathrm{P}$ e de calcário.

\begin{tabular}{cccc}
\hline Espécies & $\mathrm{P}$ & $\mathrm{Ca}$ & $\mathrm{Mg}$ \\
\hline & & $\mathrm{mg} \mathrm{vas0}^{-1}$ \\
Mucuna preta & $5,6 \mathrm{~b}$ & $1,7 \mathrm{~b}$ & $4,4 \mathrm{~b}$ \\
M. cochinchinensis & $6,9 \mathrm{a}$ & $2,7 \mathrm{a}$ & $5,9 \mathrm{a}$ \\
Feijão de porco & $6,8 \mathrm{a}$ & $1,9 \mathrm{~b}$ & $5,0 \mathrm{~b}$ \\
\hline
\end{tabular}

Médias seguidas pelas mesmas letras, nas colunas, não diferem entre si pelo teste de Tukey a $5 \%$.

Tabela 7 - Translocação média de P, Ca e Mg das leguminosas (duas plantas por vaso), em função das doses de fósforo e de calcário, cultivadas durante 60 dias em um Latossolo Amarelo.

\begin{tabular}{|c|c|c|c|c|c|c|c|c|c|}
\hline \multirow{2}{*}{$\begin{array}{c}\text { Doses de } \mathrm{P} \\
\mathrm{mg} \mathrm{dm^{-3 }}\end{array}$} & \multicolumn{9}{|c|}{ Doses de calcário, t ha-1 } \\
\hline & 0 & 4 & 8 & 0 & 4 & 8 & 0 & 4 & 8 \\
\hline & \multicolumn{3}{|c|}{$\mathrm{P}, \%$} & \multicolumn{3}{|c|}{$\mathrm{Ca}, \%$} & \multicolumn{3}{|c|}{$\mathrm{Mg}, \%$} \\
\hline 0 & $78,1 \mathrm{bB}$ & $85,7 \mathrm{aA}$ & $88,0 \mathrm{aA}$ & $91,1 \mathrm{bB}$ & $95,3 \mathrm{aA}$ & $95,3 \mathrm{aA}$ & $87,4 \mathrm{aA}$ & $87,1 \mathrm{aA}$ & $88,8 \mathrm{aA}$ \\
\hline 25 & $80,1 \mathrm{aA}$ & $81,2 \mathrm{aA}$ & $83,8 \mathrm{aA}$ & $93,1 \mathrm{aA}$ & $94,8 \mathrm{aA}$ & $94,3 \mathrm{aA}$ & $86,6 \mathrm{aA}$ & $86,6 \mathrm{aA}$ & $87,7 a A$ \\
\hline 45 & $81,3 a A$ & $83,4 a A$ & $83,8 \mathrm{aA}$ & $94,2 \mathrm{aA}$ & $95,6 \mathrm{aA}$ & $95,2 \mathrm{aA}$ & $86,7 \mathrm{aA}$ & $87,8 \mathrm{aA}$ & $887, \mathrm{aA}$ \\
\hline
\end{tabular}

Médias seguidas pelas mesmas letras minúsculas, nas colunas, e maiúsculas, nas linhas, não diferem entre si pelo teste de Tukey a $5 \%$.

Tabela 9 - Eficiência média de utilização de P, Ca e Mg das leguminosas (duas plantas por vaso), em função das espécies e das doses de calcário, cultivadas durante 60 dias em um Latossolo Amarelo.

\begin{tabular}{|c|c|c|c|c|c|c|c|c|c|}
\hline \multirow[b]{2}{*}{ Espécies } & \multicolumn{9}{|c|}{ Doses de calcário, $\mathrm{t} \mathrm{ha}^{-1}$} \\
\hline & 0 & 4 & 8 & 0 & 4 & 8 & 0 & 4 & 8 \\
\hline & \multicolumn{3}{|c|}{$\mathrm{P}, \mathrm{g}^{2} \mathrm{MS} \mathrm{mg}^{-1}$ de $\mathrm{P}$} & \multicolumn{3}{|c|}{$\mathrm{Ca}, \mathrm{g}^{2} \mathrm{MS} \mathrm{mg}^{-1}$ de $\mathrm{Ca}$} & \multicolumn{3}{|c|}{$\mathrm{Mg}, \mathrm{g}^{2} \mathrm{MS} \mathrm{mg}^{-1}$ de $\mathrm{Mg}$} \\
\hline 0 & $78,1 \mathrm{bB}$ & $85,7 a A$ & $88,0 \mathrm{aA}$ & $91,1 \mathrm{bB}$ & $95,3 a A$ & $95,3 \mathrm{aA}$ & $87,4 \mathrm{aA}$ & $87,1 \mathrm{aA}$ & $88,8 \mathrm{aA}$ \\
\hline 25 & $80,1 \mathrm{aA}$ & $81,2 \mathrm{aA}$ & $83,8 \mathrm{aA}$ & $93,1 \mathrm{aA}$ & $94,8 \mathrm{aA}$ & $94,3 a A$ & $86,6 \mathrm{aA}$ & $86,6 \mathrm{aA}$ & $87,7 a A$ \\
\hline 45 & $81,3 \mathrm{aA}$ & $83,4 \mathrm{aA}$ & $83,8 \mathrm{aA}$ & $94,2 \mathrm{aA}$ & $95,6 \mathrm{aA}$ & $95,2 \mathrm{aA}$ & $86,7 \mathrm{aA}$ & $87,8 \mathrm{aA}$ & $887, \mathrm{aA}$ \\
\hline
\end{tabular}

Médias seguidas pelas mesmas letras minúsculas, nas colunas, e maiúsculas, nas linhas, não diferem entre si pelo teste de Tukey a $5 \%$. 
Tabela 10 - Eficiência média de utilização de P, Ca e Mg das leguminosas (duas plantas por vaso), em função das doses de fósforo e de calcário, cultivadas durante 60 dias em um Latossolo Amarelo.

\begin{tabular}{|c|c|c|c|c|c|c|c|c|c|}
\hline \multirow{2}{*}{$\begin{array}{c}\text { Doses de } \\
\text { P, mg dm-3 }\end{array}$} & \multicolumn{9}{|c|}{ Doses de calcário, $\mathrm{t} \mathrm{ha}^{-1}$} \\
\hline & 0 & 4 & 8 & 0 & 4 & 8 & 0 & 4 & 8 \\
\hline & \multicolumn{3}{|c|}{$\mathrm{P}, \mathrm{g}^{2} \mathrm{MS} \mathrm{mg}^{-1}$ de $\mathrm{P}$} & \multicolumn{3}{|c|}{$\mathrm{Ca}, \mathrm{g}^{2} \mathrm{MS} \mathrm{mg}^{-1} \mathrm{de} \mathrm{Ca}$} & \multicolumn{3}{|c|}{$\mathrm{Mg}, \mathrm{g}^{2} \mathrm{MS} \mathrm{mg}^{-1} \mathrm{de} \mathrm{Mg}$} \\
\hline 0 & $7,1 \mathrm{aB}$ & $9,7 \mathrm{aA}$ & $8,3 \mathrm{aAB}$ & $91,1 \mathrm{bB}$ & $2,7 \mathrm{aA}$ & $1,6 \mathrm{aA}$ & $1,5 \mathrm{aA}$ & $4,8 \mathrm{aA}$ & $4,7 \mathrm{aA}$ \\
\hline 25 & $7,1 \mathrm{aA}$ & $5,3 \mathrm{bB}$ & $5,1 \mathrm{bB}$ & $93,1 \mathrm{aA}$ & $3,4 \mathrm{aA}$ & $1,8 \mathrm{aA}$ & $1,7 \mathrm{aA}$ & $4,9 \mathrm{aB}$ & $5,2 \mathrm{aB}$ \\
\hline 45 & $5,8 \mathrm{bA}$ & $4,9 \mathrm{bA}$ & $4,6 \mathrm{bA}$ & $94,2 \mathrm{aA}$ & $2,8 \mathrm{aA}$ & $1,8 \mathrm{aA}$ & $1,6 \mathrm{aA}$ & $5,2 \mathrm{aA}$ & $5,1 \mathrm{aA}$ \\
\hline
\end{tabular}

Médias seguidas pelas mesmas letras minúsculas, nas colunas, e maiúsculas, nas linhas, não diferem entre si pelo teste de Tukey a $5 \%$.

\section{CONCLUSÕES}

As leguminosas responderam positivamente à calagem e à adubação fosfatada. A mucuna cochinchinensis e o feijão-deporco produziram maiores quantidades de matéria seca, sendo que a primeira espécie acumulou maior quantidade de $\mathrm{P}$ e a segunda maior quantidade de $\mathrm{Ca}$.

O feijāo de porco foi a leguminosa que mais translocou nutriente, enquanto a mucuna cochinchinensis foi a espécie que apresentou maior eficiência de utilização de P, Ca e Mg na ausência da calagem.

Para solos intemperizados, com baixa concentração de P, Ca e $\mathrm{Mg}$, o feijão de porco e a mucuna cochinchinensis poderão ter melhor desempenho do que a mucuna preta, visto que apresentaram maior eficiência de translocação e de utilização desses nutrientes, respectivamente.

\section{BIBLIOGRAFIA CITADA}

Abichequer, A.D.; Bohnen, H. 1998. Eficiência de absorção, translocação e utilização de fósforo por variedades de trigo. Revista Brasileira de Ciência do Solo, 22(1): 21-26.

Alvarenga, R.C.; Costa, L.M.; Moura Filho, W.; Regazzi, A.J. 1995. Características de alguns adubos verdes de interesse para a conservação e recuperação de solos. Pesquisa Agropecuária Brasileira, 30(2):175-185.

Alves, V.M.C; Novais, R.F.; Oliveira, M.F.G.; Santana, R. 1998. Cinética e translocação de fósforo em híbridos de milho. Pesquisa Agropecuária Brasileira, 33(7):1047-1052.

Bataglia, O.C.; Camargo, C.E.O.; Oliveira, O.F.; Nagai, V.; Ramos, V.J. 1985. Resposta à calagem de três cultivares de trigo com tolerância diferencial ao alumínio. Revista Brasileira de Ciência do Solo, 9(2): 139-147.

Böhringer, A.; Tamó, M.; Dreyer, H.M. 1994. Growth and produtivity of pigionpea (Cajanus cajan) genotypes for use in alley cropping and their interactions with the environment. Experimental Agriculture, 30: 207-215.

Caldeira, M.V.W.; Rondon Neto, R.M.; Schumaker, M.V. 2002. Avaliação da eficiência nutricional de três procedências australiana de acácia negra (Acacia mearnsii DE Wild.). Revista Arvore, 26(5): 615-620.

Calegari, A.; Mondardo, A.; Bulisani, E.A.; Wildner, L.P.; Costa, M.B.B.; Alcântara, P.B.; Miyasaka, S.; Amado, J.T. 1993.
Aspectos gerais da adubação verde. In: Costa, M.B.B. (coord.) Adubação verde no Sul do Brasil. 2ed. Rio De Janeiro: AS-PTA. 346pp.

Carvalho, A.C.A.; Mochiutti, S. 1992. Leguminosas para adubação verde e cobertura do solo no estado do Amapá. In: Trabalhos e recomendaçôes da mesa redonda sobre recuperação de solos através do uso de leguminosas, 1991, Manaus, AM. Belém: EMBRAPA-CPATU/GTZ, 131pp.

Carvalho, M.M.; Saraiva, O.F.; Oliveira, F.T.T. et al. 1988. Resposta de leguminosas forrageiras tropicais à calagem e ao fósforo, em casa de vegetação. Revista Brasileira de Ciência do Solo, 12(2): 153-159.

De-Polli, H.; Chada, S.S. 1989. Adubação verde incorporada ou em cobertura na produção de milho em solo de baixo potencial de produtividade. Revista Brasileira de Ciência do Solo, 132(2): 287293.

EMBRAPA. Serviço Nacional de Levantamento e Conservação de Solos. 1999. Manual de métodos e análise de solo. 2ed. Rio de Janeiro. 212pp.

Furtini Neto, A.E.; Resende, A.V.; Vale, F.R.; Faquim, V.; Fernandes, L.A. 1999. Acidez do solo, crescimento e nutrição mineral de algumas espécies arbóreas, na fase de mudas. Revista Cerne, 5(2): $1-12$.

Gomes, T.C.A.; Pereira, J.B.M. 1992. Pesquisas sobre o uso de leguminosas no manejo e conservação de solos no Acre: diagnóstico e perspectiva. In: Trabalhos e recomendaçóes da Mesa redonda sobre recuperação de solos através do uso de leguminosas, 1991, Manaus, AM. Belém: EMBRAPA-CPATU/ GTZ, 131p.

Jarrel, W.M.; Beverly, R.B. 1981. The dillution effect in plant nutrition studies. Advances in Agronomy, 34: 197-224.

Kage, H. 1984. Adubação Verde: as observações de um lavrador. Parte II. In: Fundação Cargil. Adubação orgânica, adubação verde, e rotação de culturas no Estado de São Paulo. Campinas, p.111-1138.

Kamprath, E.J. 1967. Soil acidity and response to liming. North Caroline State University. Inst. Soil Testing Serv. Tecnical Bulletin 4: 23.

Kolling, J., Stammel, J. G., Kornelius, E. 1976. Efeito da calagem e da adubação fosfatada sobre a produção de matéria seca de leguminosas de clima tropical e sobre alguns componentes químicos do solo. In: Anais do Congresso Brasileiro de Ciência 


\section{ACTA}

do Solo, 15. Campinas, 1975. Campinas, Sociedade Brasileira de Ciência do Solo. p.255.

Loneragan, J.F; Asher, C.J. 1967. Response of plants to phosphate concentration in solution culture: II. Rate of phosphate absorption and its relation to growth. Soil Science, 103: 311318.

Machado, C.T.T. 2000. Caracterização de genótipos de milho quanto a parâmetros morfológicos, fisiológicos e microbiológicos associados à eficiência de absorção e uso de fósforo. Tese de Doutorado, Universidade Federal Rural do Rio de Janeiro - UFRRJ, Rio de Janeiro, RJ. 387pp.

Machado, C.T.T.; Guerra, J.G.M.; Almeida, D.L.; Machado, A.T. 1999. Variabilidade entre genótipos de milho para eficiência no uso de fósforo. Bragantia, 58(1): 109-124.

Martinez, H.E.P; Novais, R.F.; Sacramento, L.V.S.; Rodrigues, L.A. 1993. Comportamento de variedades de soja cultivadas sob diferentes níveis de fósforo: II. Translocação do fósforo absorvido e eficiência nutricional. Revista Brasileira de Ciência do Solo, 17(2): 239-244.

Muller, N.R.M; Muller, A.A.; Oliveira, R.P. 1992. In: Trabalhos e recomendações da mesa redonda sobre recuperação de solos através do uso de leguminosas, 1991, Manaus, AM. Belém, PA: EMBRAPA-CPATU/GTZ. 131pp.
Rodrigues, T.E. 1996. Solos da Amazônia. In: Alvarez V., V.H.; Fontes, L.E.F.; Fontes, M.P.F (eds). O solo nos grandes dominios morfoclimáticos do Brasil e o desenvolvimento sustentado. Viçosa: UFV/DPS/SBCS, p.19-60.

Sanches, P.A. 1981. Suelos del trópico: características y manejo. San José, IICA, 634pp.

Vieira, L.S.; Santos, P.C.T. 1987. Amazônia: seus solos e outros recursos naturais. São Paulo, Ceres. 420pp.

Vilela, L.; Anghinoni, I. 1984. Morfologia do sistema radicular e cinética de absorção de fósforo em cultivares de soja, afetadas pela interação alumínio-fósforo. Revista Brasileira de Ciência do Solo, 8(1): 91-96.

Zonta, E.P.; Machado, A.A. 1991. Sistema de análise estatística para microcomputadores (SANEST). Pelotas: UFPel - Departamento de Matemática e Estatística. 101pp.

Recebido em 20/09/2002

Aceito em 02/03/2007 
